\title{
The associations of high birth weight with blood pressure and hypertension in later life: a systematic review and meta-analysis
}

\author{
Yong Zhang ${ }^{1,2}$, Hui $\mathrm{Li}^{2}$, Shang-jing $\mathrm{Liu}^{2}$, Guang-jian $\mathrm{Fu}^{2}$, Yong Zhao, ${ }^{1,2}$, Yao-Jie Xie ${ }^{3}$, Yi Zhang ${ }^{1,2}$ \\ and Ying-xiong Wang ${ }^{1}$
}

The 'fetal origin hypothesis' suggests that metabolic diseases are directly related to poor nutritional status in early life. Thus, a high birth weight (HBW) may pose a lower risk than normal birth weight. Overweight and overnutrition are among the most widely recognized risk factors of metabolic diseases. To explore the possible effects of HBW on blood pressure and hypertension, a systematic review was performed. The PubMed and Embase databases were searched for relevant studies. The outcomes included systolic blood pressure (SBP), diastolic blood pressure (DBP) and hypertension. We included all of the studies that assessed the differences in outcomes for children aged $>1$ year between those born with normal birth weight (birth weight between 2500 and $4000 \mathrm{~g}$ or between the 10th and 90th percentiles for their gestational age) and those born with HBW (birth weight $\geqslant 4000 \mathrm{~g}$ or $\geqslant 90$ th percentile for their gestational age). The outcomes were analyzed descriptively and by conducting a meta-analysis. Thirty-one studies satisfied the inclusion criteria. The mean difference in blood pressure and the relative risk of hypertension between individuals with HBW and individuals with normal birth weight was inversely associated with age. SBP and DBP, as well as the prevalence of hypertension, were higher in younger children with HBW but lower in older adults with HBW compared with individuals with normal birth weight. The findings suggested that an individual with HBW is prone to hypertension and higher blood pressure during childhood. However, a 'catch-down' effect in the elevation of blood pressure is observed in subjects with HBW as they grow older. Thus, older individuals with HBW are less susceptible to hypertension than those with normal birth weight.

Hypertension Research (2013) 36, 725-735; doi:10.1038/hr.2013.33; published online 18 April 2013

Keywords: blood pressure; high birth weight; meta-analysis; systematic review

\section{INTRODUCTION}

Birth weight is an important indicator of the nutrition and growth status of fetuses. Poor nutrition in pregnancy often leads to low birth weight, whereas overnutrition leads to high birth weight (HBW). ${ }^{1,2}$ Barker et al. $^{3}$ showed that reduced fetal growth increases cardiovascular disease mortality in adults. The 'fetal origin hypothesis' of adult diseases was introduced to explain the relationship between low birth weight and adult diseases. ${ }^{4}$ Numerous studies on low birth weight have shown that birth weight is inversely related to the risk of metabolic syndrome, ${ }^{5-8}$ which is defined as a combination of at least three of the following five components: obesity, high blood pressure, high serum triglycerides, low serum high-density lipoprotein and impaired glucose or insulin resistance. 9 The 'fetal origin hypothesis' also suggests that an adverse intrauterine environment (for example, characterized by poor nutrition) may reduce fetal growth by programming metabolic development and thus lead to lifelong physiological changes that predispose the body to metabolic diseases. $^{10}$

HBW, which is also termed macrosomia or large for gestational age in obstetrics, is defined as birth weight $>4000 \mathrm{~g}$ or $>90$ th percentile of gestational age. ${ }^{11} \mathrm{HBW}$ is usually associated with maternal obesity, excessive gestational weight gain, or gestational diabetes mellitus. ${ }^{12}$ As the prevalence of maternal obesity and gestational diabetes mellitus has increased worldwide, the prevalence of HBW has also increased. ${ }^{13-14}$

According to the 'fetal origin hypothesis', HBW may elicit effects on blood pressure that differ from those for individuals with low birth weight and normal birth weight (NBW; defined as birth weight between $2500 \mathrm{~g}$ and $4000 \mathrm{~g}$ ); that is, subjects with HBW may have a lower risk of metabolic diseases than those with NBW. However, overnutrition and overweight in multiple stages of an individual's life are key risk factors for metabolic syndromes. Therefore, conflicting

\footnotetext{
${ }^{1}$ School of Public Health and Health Management, Chongqing Medical University, Chongqing, China; ${ }^{2}$ China Network of Effective Health Care Research Consortium, Chongqing Medical University, Chongqing, China and ${ }^{3}$ Department of Community Medicine and School of Public Health, The University of Hong Kong, Hong Kong

Correspondence: Professor Y-x Wang, School of Public Health and Health Management, Chongqing Medical University, No. 1 Yixueyuan Road, Yuzhong District, Chongqing 400016, China.

E-mail: wyx61221@yahoo.com.cn

Received 7 August 2012; revised 6 January 2013; accepted 9 January 2013; published online 18 April 2013
} 
hypotheses have been proposed to explain the relationship between HBW and blood pressure. However, most published studies have focused primarily on low birth weight without considering subjects with HBW, or they have mixed subjects with HBW into the NBW group, making the comparison more heterogeneous. ${ }^{7,15-18}$

We performed this systematic review to clarify the relationship between HBW and blood pressure, to explain the paradox of the 'fetal origin hypothesis' for HBW, and to assess the effects of HBW on blood pressure and hypertension in later life compared with individuals of NBW.

\section{METHODS}

The systematic review and meta-analysis were conducted by following the Meta-Analysis of Observational Studies in Epidemiology Group checklist, ${ }^{19}$ a checklist that includes the processes by which the data are obtained, the analysis is performed, and the findings are reported in meta-analyses.

We performed a literature search in the PubMed and Embase databases using the following terms: ('birth weight' OR 'birth size' OR 'macrosomia' OR 'large for gestational age') NOT ('preterm birth' OR 'low birth weight' OR 'small for gestational age' OR 'prematurity' OR 'twin') AND ('metabolic syndrome' OR 'hypertension' OR 'cardiovascular disease' OR 'blood pressure'). The search was limited to studies with human subjects that were published in the English language. The publication dates were before October 2012. Two authors screened the search results independently. The screened results from each reviewer were combined after deliberation. The full text articles were retrieved and checked for eligibility.

To be eligible for inclusion, studies had to satisfy the following criteria: (1) the study was an original report on the relationship(s) between birth weight and blood pressure or hypertension; (2) the subjects were singletons born at full-term; (3) the outcomes were investigated at ages $>1$ year; (4) HBW and NBW were distinctly defined with HBW as $\geqslant 4000 \mathrm{~g}$ or $\geqslant$ the 90th percentile for gestational age and NBW as $2500-4000 \mathrm{~g}$ or the 10-90th percentiles for gestational age.

Furthermore, a manual search was conducted among the reference lists for all of the eligible studies and related reviews. The overall process is illustrated in Figure 1.

From the studies that were considered eligible for this review, two authors collected information independently using standardized sheets. The means and the s.d. values for blood pressure were determined directly or by performing calculations. The numbers of participants with hypertension in each group were obtained for the relative risk (RR) calculations. If possible, all of the original data were extracted using the minimum subgroups.

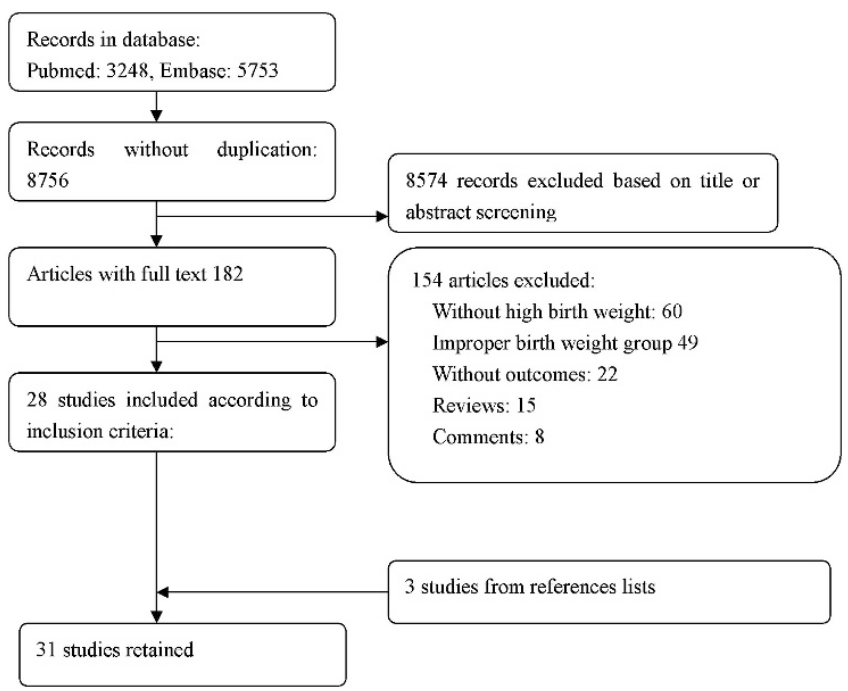

Figure 1 Flow chart of literature review.
The Newcastle-Ottawa quality assessment scale was used for quality assessment. ${ }^{20}$ Eight factors were assessed, and each satisfactory factor received one star (a maximum of nine stars were used).

We used STATA version 11.0 (Stata Corp., College Station, TX, USA) for the data analysis. The heterogeneity among the studies was assessed using $Q$ and $I^{2}{ }^{21}$ The data were synthesized using a random-effects model or a fixed-effect model according to the heterogeneity. Meta-regression was used to confirm the heterogeneity and the relationship between the characteristics of the studies and the effects of HBW.

\section{RESULTS}

\section{Overall}

We obtained 8756 records of studies from the PubMed and Embase databases in the computer search. After the abstracts of the studies were screened, 182 potentially relevant studies remained. We further assessed the details, performed a manual search, and determined that 31 studies satisfied the inclusion criteria. We primarily excluded studies because they lacked an HBW group. We also excluded those with inappropriate birth weight groups (that is, the cutoff points for HBW and NBW did not satisfy the inclusion criteria).

Blood pressure and/or hypertension data were obtained from 31 studies, and some of them were included in this review. In particular, six studies provided mean values but no standard deviations; another study provided $Z$ scores. These seven studies were not included in the meta-analysis.

Four studies focused on overweight or obesity. Furthermore, at least one study included the following types of participants: offspring with gestational diabetes mellitus, children with abnormal urinalysis, individuals with type 1 diabetes and women with pregnancy-induced hypertension. The characteristics of the 31 studies are summarized in Table 1

The quality of the studies in terms of subject selection, as well as the comparability and reliability of outcomes, is summarized in Table 2 .

\section{Systolic blood pressure}

Fourteen studies provided 24 mean differences (MDs) in SBP between individuals with HBW and NBW. The meta-analysis of random effects revealed an overall $\mathrm{MD}$ of $-0.25 \mathrm{~mm} \mathrm{Hg}$ (95\% confidence interval, $0.92,0.42)$ with considerable heterogeneity $\left(I^{2}=79.3 \%, Q\right.$-statistic: $P<0.0001$ ). The subgroup analysis by age (using the mean age from each study) showed that only the age group $>40$ years exhibited low heterogeneity. As the individuals grew older, the MD in SBP changed from positive to negative. The results indicate that HBW is associated with higher SBP in younger subjects, but lower SBP in older subjects (Figure 2)

To explore the sources of heterogeneity in the pooled MD, we performed a meta-regression analysis, which revealed that age explains the majority of the variance between the studies (value of adjusted $R^{2}$ ). The regression coefficient also indicates that age was inversely associated with the MD in SBP (Table 3).

Among the seven studies excluded from the meta-analysis, all five studies on adults showed that SBP was lower among individuals with HBW than individuals with NBW (statistical test unavailable). ${ }^{45-49}$ One of the two studies on children showed that SBP was higher among those with HBW than those with NBW (non-significant), ${ }^{23}$ in agreement with the results shown in Figure 2.

\section{Diastolic blood pressure}

Thirteen studies provided 23 MDs in DBP between those with HBW and those with NBW. The pooled MD was $0.20 \mathrm{~mm} \mathrm{Hg}(95 \%$ 


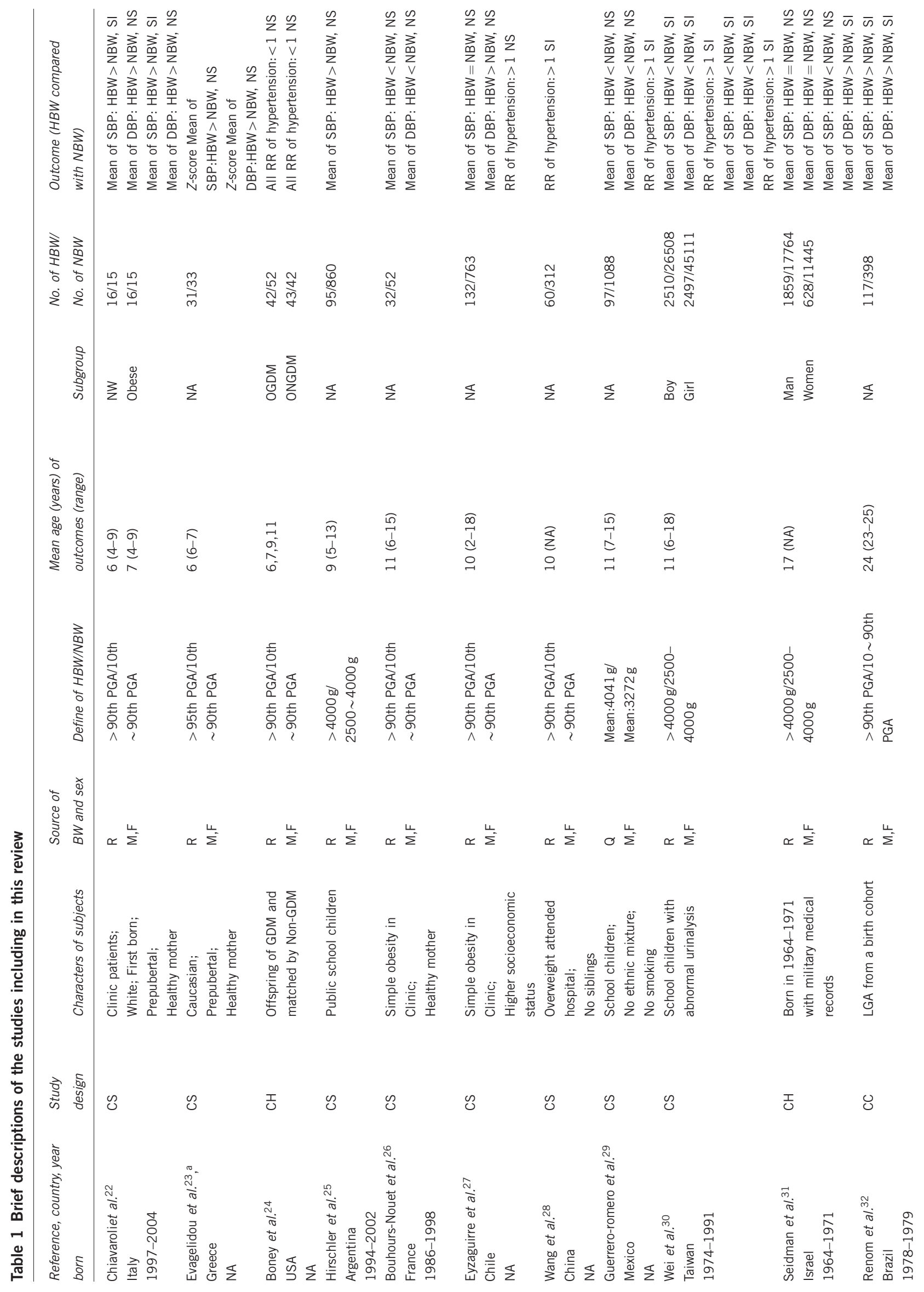




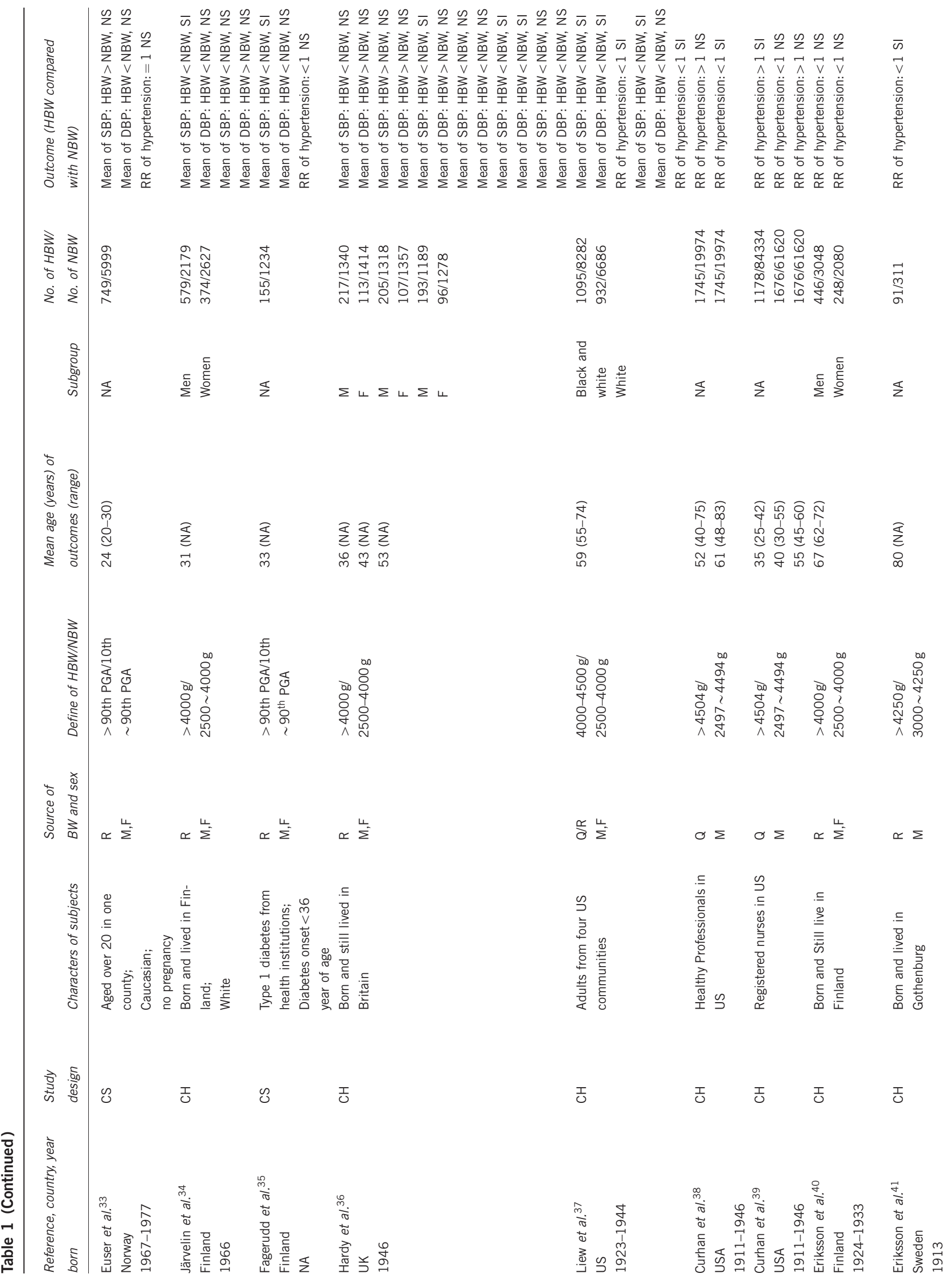




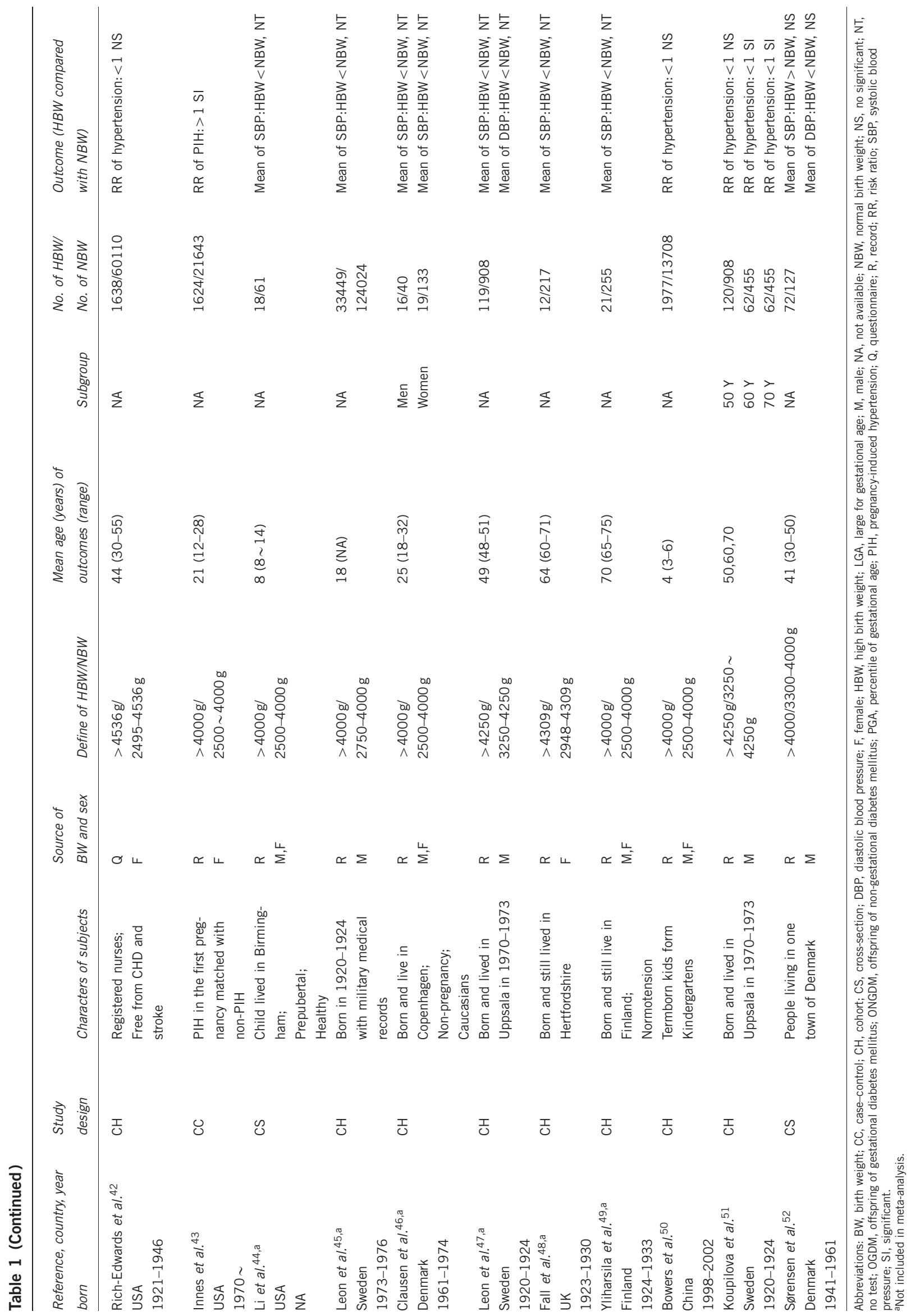


Table 2 Assessment of quality of the study

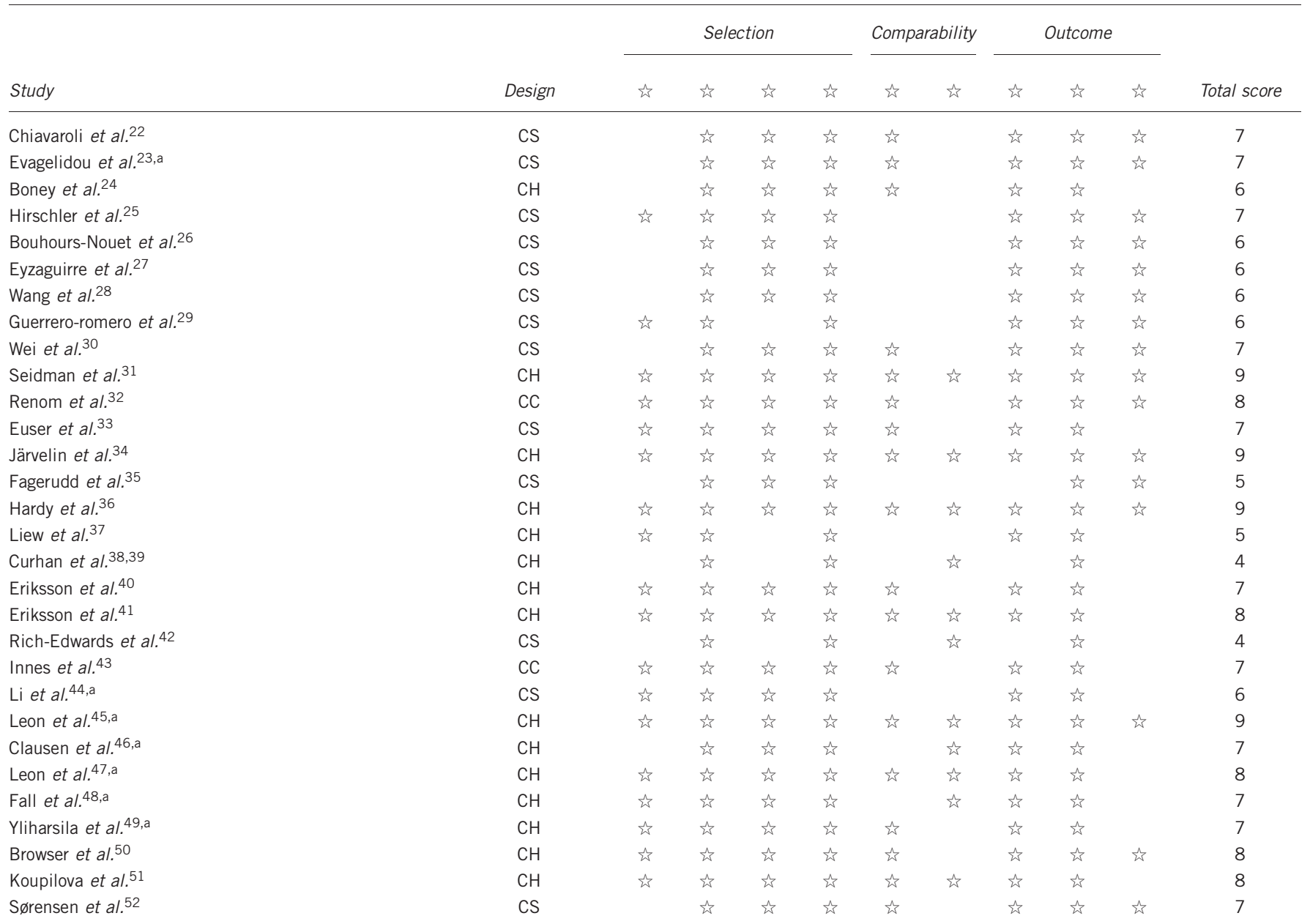

Abbreviations: $\mathrm{CC}$, case-control; $\mathrm{CH}$, cohort; $\mathrm{CS}$, cross-section.

a Not included in meta-analysis.

confidence interval, $-0.23,0.62)$. The heterogeneity among these studies was also high $\left(I^{2}=72.6 \%\right.$, Q-statistic: $\left.P<0.0001\right)$. A subgroup analysis by age showed that the heterogeneity in each group was low. With increasing age, the $\mathrm{MD}$ in $\mathrm{DBP}$ changed from positive to negative. The results indicate that HBW is associated with higher DBP in younger subjects but lower DBP in older subjects (Figure 3).

The same characteristics of the subjects and the studies mentioned above were included in the meta-regression. The results of the meta-regression showed that age might be the main factor contributing to the significant heterogeneity. The regression coefficient also showed that age was inversely associated with the MD in DBP (Table 4).

Of the two studies that were excluded from the meta-analysis, one study reported that adults with HBW had lower DBP than those with NBW (statistical test unavailable). ${ }^{47}$ The other study revealed that DBP was higher in children with HBW than those with NBW (not a statistically significant difference) ${ }^{23}$ (Figure 3 ).

\section{Hypertension}

Fifteen studies with 31 RRs for hypertension associated with HBW and NBW were included. The overall RR combination was 1.00 (95\% confidence interval, $0.931,1.06)$ with significant heterogeneity $\left(I^{2}=63.8 \%\right.$, Q-statistic: $\left.P<0.0001\right)$. The subgroup analysis showed that there was heterogeneity in the age group $>40$ years. With increasing age, the RR for hypertension changed from $>1$ to $<1$. The results indicate that HBW is associated with a higher risk of hypertension in younger subjects but a lower risk in older subjects (Figure 4).

The sources of heterogeneity were investigated by performing meta-regression analysis. The results of the meta-regression show that age was the primary, statistically significant source of heterogeneity (Table 5). Age was inversely associated with the RR of hypertension, indicating that older subjects with HBW had a lower risk of hypertension than those with NBW (Figure 4).

\section{DISCUSSION}

In this review, we primarily aimed to assess the effects of HBW on blood pressure and hypertension by summarizing the current evidence from published studies. However, substantial heterogeneity made it inappropriate to synthesize all of the data. In particular, the subgroup analysis showed that some subgroups exhibited high heterogeneity. Further meta-regression analysis revealed that age was consistently associated with the effects of HBW on blood pressure and the risk of hypertension.

The results of both the meta-combination and meta-regression analysis revealed that age was inversely associated with the effects of HBW on blood pressure and hypertension. The results indicate that HBW has contrasting effects on blood pressure and hypertension in 


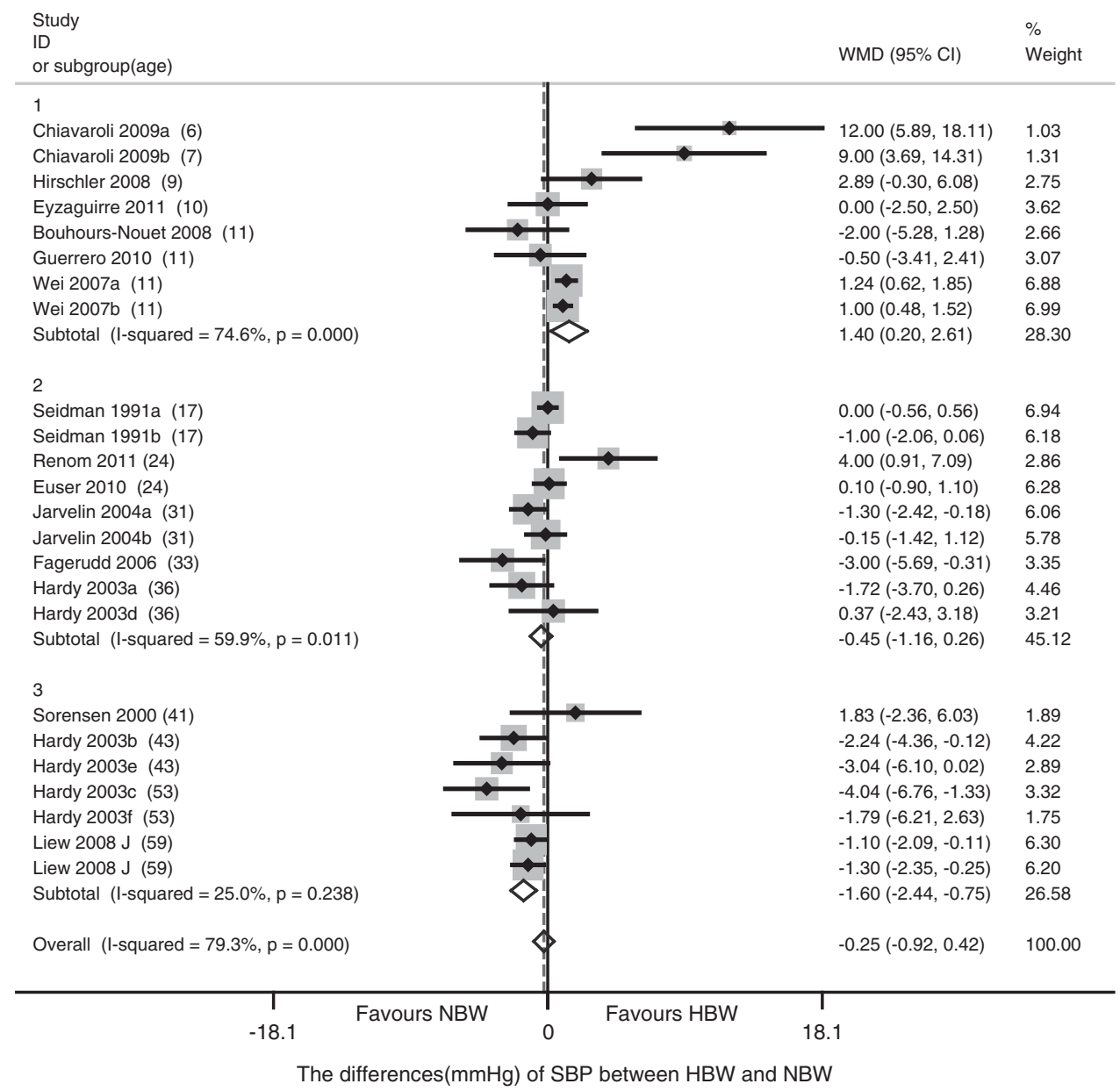

Figure 2 The differences of systolic blood pressure (SBP) between HBW and NBW in meta-analysis. Studies ordered by mean ages at which the outcome was measured. The pooled MDs were calculated by means of a random effects model; 95\% confidence intervals $(\mathrm{Cl})$ are shown in parentheses and as horizontal bars. HBW, high birth weight, NBW, normal birth weight, WMD, weighted mean difference.

Table 3. Meta-regression for the MD of SBP between HBW and NBW

\begin{tabular}{|c|c|c|c|c|c|c|}
\hline Predictor & Coefficient & s.e. & $t$ & $P$ & $95 \% \mathrm{Cl}$ & Adj. R-squared \\
\hline \multicolumn{7}{|c|}{ Characters of subjects } \\
\hline Age & -0.065 & 0.023 & -2.86 & 0.009 & $-0.112,-0.018$ & $67.68 \%$ \\
\hline Gender 2 & -1.339 & 1.188 & -1.13 & 0.272 & $-3.803,1.124$ & $-11.67 \%$ \\
\hline Healthy status & 0.871 & 1.260 & 0.69 & 0.497 & $-1.741,3.483$ & $1.11 \%$ \\
\hline Study quality & -0.218 & 0.367 & -0.59 & 0.559 & $-0.979,0.543$ & $-15.55 \%$ \\
\hline Sample size & 0.000 & 0. 000 & 0.58 & 0.570 & $-0.000,0.000$ & $2.45 \%$ \\
\hline Publication year & 0.111 & 0.097 & 1.14 & 0.266 & $-0.090,0.312$ & $-11.54 \%$ \\
\hline Study design & 1.744 & 0.963 & 1.81 & 0.084 & $-0.254,3.742$ & $41.65 \%$ \\
\hline
\end{tabular}

Abbreviations: MD, mean difference, SBP, systolic blood pressure; HBW, high birth weight, NBW, normal birth weight.

Gender $1: M+F=1, F=0$; Gender 2: $M=1, F=0$; Healthy status: from ordinary population=0, from clinic population $=1$; proportion of HBW: number of HBW/(number of HBW + number of NBW); study quality: NOS score; sample size: number of HBW + number of NBW; study design: cohort $=0$, cross-section and case-control $=1$ Regression method: ReML (residual maximum likelihood); Regression model: univariate regression with random-effects. 


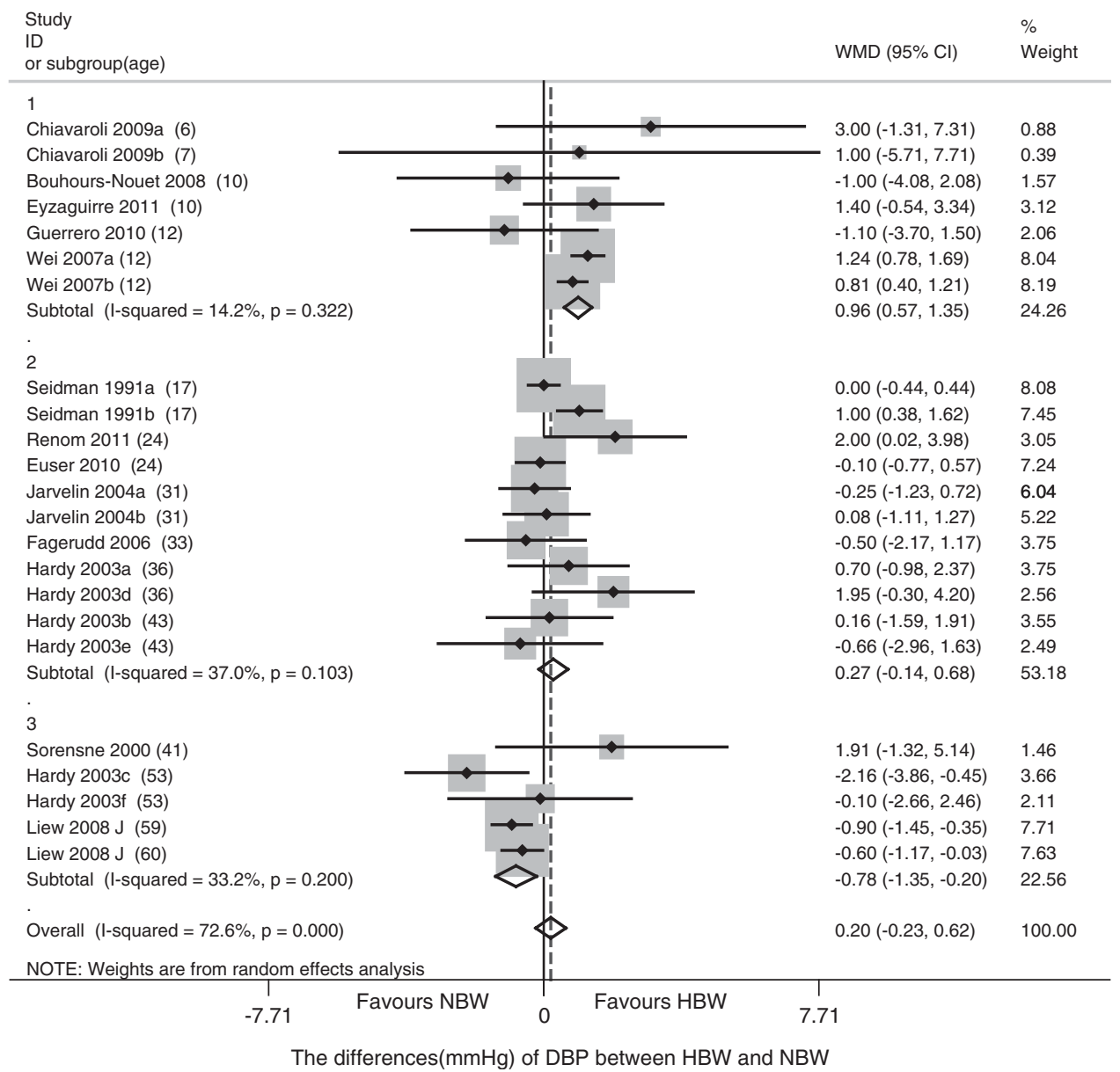

Figure 3 The differences of diastolic blood pressure (DBP) between HBW and NBW in meta-analysis. Studies ordered by the mean age at which the outcome was measured. The pooled MDs were calculated by means of a random-effects model; $95 \%$ confidence intervals $(\mathrm{Cl})$ are shown in parentheses and as horizontal bars. HBW, high birth weight; NBW, normal birth weight, WMD, weighted MD.

Table 4 Meta-regression for the MD of DBP between HBW and NBW

\begin{tabular}{|c|c|c|c|c|c|c|}
\hline Predictor & Coefficient & s.e. & $t$ & $P$ & $95 \% \mathrm{Cl}$ & Adj. R-squared \\
\hline \multicolumn{7}{|c|}{ Characters of subjects } \\
\hline Age & -0.034 & 0.008 & -4.42 & 0.000 & $-0.050,-0.018$ & $77.92 \%$ \\
\hline Gender 1 & -0.581 & 0.414 & -1.40 & 0.175 & $-1.442,0.280$ & $27.04 \%$ \\
\hline Gender 2 & -0.019 & 0.465 & -0.04 & 0.968 & $-0.986,0.949$ & $-10.45 \%$ \\
\hline Healthy status & 0.911 & 0.409 & 2.22 & 0.037 & $-0.059,1.763$ & $39.54 \%$ \\
\hline \multicolumn{7}{|c|}{ Characters of studies } \\
\hline$\%$ HBW & 1.144 & 2.868 & 0.40 & 0.694 & $-4.820,7.108$ & $-10.36 \%$ \\
\hline Study quality & 0.136 & 0.135 & 1.01 & 0.323 & $-0.144,0.417$ & $5.30 \%$ \\
\hline Sample size & 0.000 & 0.000 & 1.42 & 0.169 & $-0.000,0.000$ & $19.10 \%$ \\
\hline Publication year & -0.011 & 0.036 & -0.31 & 0.759 & $-0.086,0.064$ & $-9.55 \%$ \\
\hline Study design & 0.491 & 0.430 & 1.14 & 0.266 & $-0.403,1.386$ & $13.16 \%$ \\
\hline
\end{tabular}

Abbreviations: $\mathrm{Cl}$, confidence interval; DBP, diastolic blood pressure; HBW, high birth weight, MD, mean difference; NBW, normal birth weight.

Gender 1: $M+F=1, F=0$; Gender 2: $M=1, F=0$; healthy status: from ordinary population=0, from clinic population $=1$; proportion of HBW: number of HBW/(number of HBW + number of NBW); study quality: NOS score; sample size: number of HBW + number of NBW; study design: cohort =0, cross-section and case-control =1 Regression method: ReML (residual maximum likelihood); Regression model: univariate regression with random-effects. 


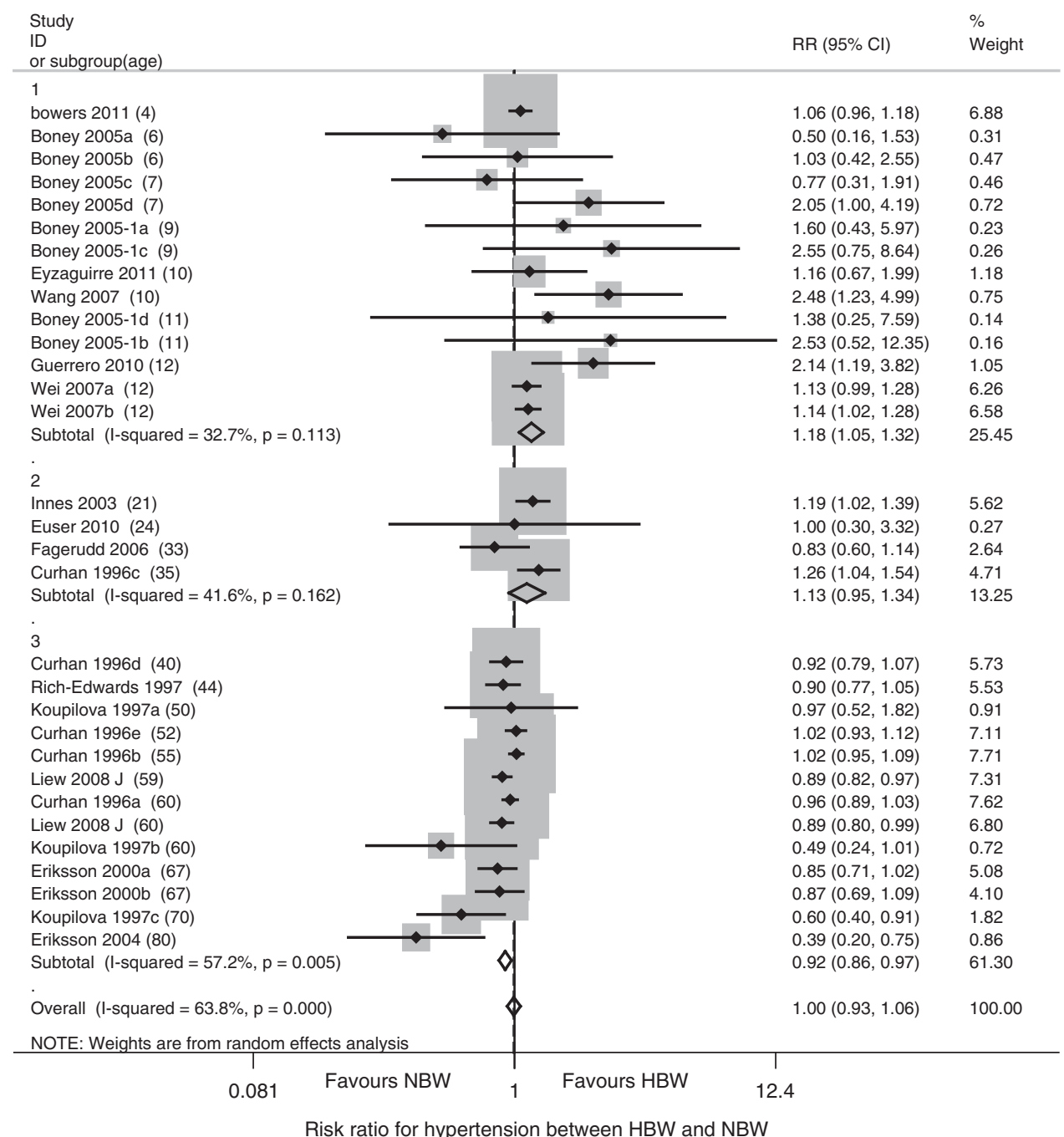

Figure 4 Risk ratio for hypertension between HBW and NBW in meta-analysis. Studies ordered by the mean age at which the event was checked. The pooled risk ratios were calculated by means of a random-effects model; $95 \%$ confidence intervals $(\mathrm{Cl})$ are shown in parentheses and as horizontal bars. HBW, high birth weight, NBW, normal birth weight, RR, risk ratio.

Table 5 Meta-regression for the RR of hypertension between HBW and NBW

\begin{tabular}{|c|c|c|c|c|c|c|}
\hline Predictor & Coefficient & s.e. & $t$ & $P$ & $95 \% \mathrm{Cl}$ & Adj. R-squared \\
\hline \multicolumn{7}{|c|}{ Characters of subjects } \\
\hline Age & -0.006 & 0.002 & -3.58 & 0.001 & $-0.009,-0.003$ & $79.59 \%$ \\
\hline Gender 2 & -0.276 & 0.148 & -1.87 & 0.072 & $-0.578,0.026$ & $-23.71 \%$ \\
\hline Healthy status & 0.138 & 0.152 & 0.90 & 0.373 & $-0.174,0.449$ & $11.85 \%$ \\
\hline Study quality & -0.011 & 0.048 & -0.24 & 0.813 & $-0.109,0.086$ & $-55.70 \%$ \\
\hline Sample size & 0.000 & 0.000 & 0.01 & 0.995 & $-0.000,0.000$ & $-43.89 \%$ \\
\hline Publication year & 0.018 & 0.012 & 1.47 & 0.153 & $-0.007,0.044$ & $-48.52 \%$ \\
\hline Study design & 0.194 & 0.121 & 1.60 & 0.121 & $-0.054,0.442$ & $31.16 \%$ \\
\hline
\end{tabular}

Abbreviations: $\mathrm{Cl}$, confidence interval; $\mathrm{HBW}$, high birth weight, NBW, normal birth weight; RR, relative risk.

Gender $1: M+F=1, F=0$; Gender 2: $M=1, F=0$; Healthy status: from ordinary population =0, from clinic population $=1$; proportion of $\mathrm{HBW}$ : number of $\mathrm{HBW} /(\mathrm{number}$ of $\mathrm{HBW}+$ number of NBW); study quality: NOS score; sample size: number of HBW + number of NBW; study design: cohort $=0$, cross-section and case-control $=1$ Regression method: ReML (residual maximum likelihood); Regression model: univariate regression with random-effects. 
younger subjects compared with older subjects. In the younger subjects, HBW resulted in higher blood pressure and a higher risk of hypertension than NBW. In older subjects, HBW led to lower blood pressure and a lower risk of hypertension.

HBW, which indicates overnutrition in the initial stage of life, raised blood pressure and the risk of hypertension in early life. Another published systematic review also reported that newborns with higher birth weight had higher blood pressure. ${ }^{16}$ Although an age-related increase in blood pressure has been observed in almost every population, ${ }^{53}$ the increase in blood pressure associated with HBW seems to be attenuated or reversed with increasing age. In other words, a 'catch-down' effect occurs in blood pressure and the risk of hypertension when individuals with HBW grow older.

In fact, a 'catch-down' phenomenon is common in babies born large. For example, large for gestational age babies usually experience a postnatal 'catch-down' in height, weight and so on. ${ }^{54,55}$ The increase in blood pressure likely follows the same pattern for weight or height in large babies, with this increase subsiding after several years.

Evidence has shown that subjects with HBW are usually bigger in size and heavier in weight. ${ }^{56}$ However, these subjects are more metabolically healthy when they grow older because they have more lean mass than adipose tissue. ${ }^{57}$ This condition may lead to lower blood pressure in subjects with HBW compared with those who have the same BMI but were born with NBW. Another possible explanation is that the difference in blood pressure between those with HBW and NBW is very subtle in childhood, and other factors compensate for these differences later in life.

To the best of our knowledge, this review is the first to discuss the association of HBW with blood pressure and hypertension over the life course. This review reveals that age is an important factor that is associated with birth weight and affects blood pressure and hypertension. Considering the conflicting implications of HBW (that is, an overweight status in the early stage of life does not correspond to a high risk of hypertension in later stages of life), we propose that the 'catch-down' effect in blood pressure might attenuate the risk of hypertension associated with HBW.

However, this review has some limitations. First, only studies published in English were eligible for the study, which may have introduced selection bias. Second, given that age is the main source of heterogeneity, subgroup meta-analyses of more specific age groups may be more effective when additional evidence is available. Third, subjects with HBW are a heterogeneous population that includes both individuals from diabetic pregnancies or obese mothers and normal large infants with birth weights that align with their growth potential. Considering that information on the etiology of fetal overgrowth is not reported in most studies, the effects of specific causes of HBW on blood pressure remain unclear.

\section{CONCLUSION}

The MDs in blood pressure and in the RR of hypertension between individuals with HBW and NBW are inversely associated with age. Blood pressure and the risk of hypertension are higher among individuals with HBW during childhood but lower during adulthood. This finding may be partially attributed to the 'catch-down' effect in the elevation of blood pressure when the subjects with HBW grow older.

\section{CONFLICT OF INTEREST}

The authors declare no conflicts of interest.

\section{ACKNOWLEDGEMENTS}

This study was supported by the National Natural Science Foundation of China (Grant No. 30901189) and the Effective Health Care Research Program Consortium of China (Chongqing) RPC.

1 Han Z, Mulla S, Beyene J, Liao G, McDonald SD. Maternal underweight and the risk of preterm birth and low birth weight: a systematic review and meta-analyses. Int $J$ Epidemiol 2005; 40: 65-101.

2 Ludwig DS, Currie J. The association between pregnancy weight gain and birthweight: a within-family comparison. Lance 2010; 376: 984-990.

3 Barker DJ, Osmond C, Simmonds SJ, Wield GA. The relation of small head circumference and thinness at birth to death from cardiovascular disease in adult life. BMJ 1993; 306: 422-426.

4 Von Mutius E. Fetal origins of adult disease. Thorax 2001; 56: 153-157.

5 Harder T, Rodekamp E, Schellong K, Dudenhausen JW, Plagemann A. Birth weight and subsequent risk of type 2 diabetes: a meta-analysis. Am J Epidemiol 2007; 165: 849-857.

6 Gamborg M, Byberg L, Rasmussen F, Andersen PK, Baker JL, Bengtsson C, Canoy D, Drøyvold W, Eriksson JG, Forsén T, Gunnarsdottir I, Järvelin MR, Koupil I, Lapidus L, Nilsen TI, Olsen SF, Schack-Nielsen L, Thorsdottir I, Tuomainen TP, Sørensen TI. Birth weight and systolic blood pressure in adolescence and adulthood: meta-regression analysis of sex- and age-specific results from 20 Nordic studies. Am J Epidemiol 2007; 166: 634-645

7 Huxley R, Owen CG, Whincup PH, Cook DG, Rich-Edwards J, Smith GD, Collins R. Is birth weight a risk factor for ischemic heart disease in later life? The Am J Clin Nutr 2002: 85: 807-814.

8 Whincup PH, Kaye SJ, Owen CG, Huxley R, Cook DG, Anazawa S, Barrett-Connor E, Bhargava SK, Birgisdottir BE, Carlsson S, de Rooij SR, Dyck RF, Eriksson JG, Falkne B, Fall C, Forsén T, Grill V, Gudnason V, Hulman S, Hyppönen E, Jeffreys M, Lawlor DA, Leon DA, Minami J, Mishra G, Osmond C, Power C, Rich-Edwards JW, Roseboom TJ, Sachdev HS, Syddall H, Thorsdottir I, Vanhala M, Wadsworth M, Yarbrough DE. Birth weight and risk of type 2 diabetes: a systematic review. JAMA 2008; 300: 2886-2897.

9 Luo ZC, Xiao L, Nuyt AM. Mechanisms of developmental programming of the metabolic syndrome and related disorders. World J Diab 2010; 1: 89-98.

10 Phillips DI. Birth weight and the future development of diabetes. A review of the evidence. Diab Care 1998; 21: B150-B155.

11 Evagelidou EN, Kiortsis DN, Bairaktari ET, Giapros VI, Cholevas VK, Tzallas CS, Andronikou SK. Lipid profile, glucose homeostasis, blood pressure, and obesityanthropometric markers in macrosomic offspring of nondiabetic mothers. Diab Care 2006; 29: 1197-1201.

12 Vela-Huerta MM, San Vicente-Santoscoy EU, Guizar-Mendoza JM, Amador-Licona N Aldana-Valenzuela C, Hernnández J. Leptin, insulin, and glucose serum levels in large-for-gestational-age infants of diabetic and non-diabetic mothers. JPEM 2008; 21: 17-22.

13 Tsoi E, Shaikh H, Robinson S, Teoh TG. Obesity in pregnancy: a major healthcare issue. Postgraduate Med J 2010; 86: 617-623.

14 Sarwer DB, Allison KC, Gibbons LM, Markowitz JT, Nelson DB. Pregnancy and obesity: a review and agenda for future research. J Womens Health 2002 2006; 15: 720-733.

15 Adair LS, Martorell R, Stein AD, Hallal PC, Sachdev HS, Prabhakaran D, Wills AK, Norris SA, Dahly DL, Lee NR, Victora CG. Size at birth, weight gain in infancy and childhood, and adult blood pressure in 5 low- and middle-income-country cohorts: when does weight gain matter? The Am J Clin Nutr 2009; 89: 1383-1392.

16 Law CM, Shiell AW. Is blood pressure inversely related to birth weight? The strength of evidence from a systematic review of the literature. J Hypertension 1996; 14 935-941.

17 Huxley RR, Shiell AW, Law CM. The role of size at birth and postnatal catch-up growth in determining systolic blood pressure: a systematic review of the literature. J Hypertension 2000; 18: 815-831.

18 Huxley R, Neil A, Collins R. Unravelling the fetal origins hypothesis: is there really an inverse association between birthweight and subsequent blood pressure? Lance 2002 360: 659-665

19 Stroup DF, Berlin JA, Morton SC, Olkin I, Williamson GD, Rennie D, Moher D, Becker BJ, Sipe TA, Thacker SB. Meta-analysis of observational studies in epidemiology: a proposal for reporting. JAMA 2000; 283: 2008-2012.

20 Wells GA, Shea B, O'Connell D, Peterson J, Welch V, Losos M, Tugwell P. The Newcastle-Ottawa Scale (NOS) for assessing the quality of nonrandomised studies in meta-analyses, 2000.

21 Higgins JPT, Thompson SG, Deeks JJ, Altman DG. Measuring inconsistency in metaanalyses. BMJ 2003; 327: 557-560.

22 Chiavaroli V, Giannini C, AE D, de GT, Chiarelli F, Mohn A. Insulin resistance and oxidative stress in children born small and large for gestational age. Pediatrics 2009, 124: 695-702

23 Evagelidou EN, Giapros VI, Challa AS, Cholevas VK, Vartholomatos GA, Siomou EC, Kolaitis NI, Bairaktari ET, Andronikou SK. Prothrombotic state, cardiovascular, and metabolic syndrome risk factors in prepubertal children born large for gestational age. Diab Care 2010; 33: 2468-2470. 
24 Boney CM, Verma A, Tucker R, Vohr BR. Metabolic syndrome in childhood: association with birth weight, maternal obesity, and gestational diabetes mellitus. Pediatrics 2005; 115: 290-296.

25 Hirschler V, Bugna J, Roque M, Gilligan T, Gonzalez C. Does low birth weight predict obesity/overweight and metabolic syndrome in elementary school children? Arch Med Res 2008; 39: 796-802.

26 Bouhours-Nouet N, Dufresne S, de CF, Mathieu E, Douay O, Gatelais F, Rouleau S, Coutant R. High birth weight and early postnatal weight gain protect obese children and adolescents from truncal adiposity and insulin resistance: metabolically healthy but obese subjects? Diab Care 2008; 31: 1031-1036.

27 Eyzaguirre F, Bancalari R, Román R, Silva R, Youlton R, Urquidi C, García H, Mericq V. Prevalence of components of the metabolic syndrome according to birthweight among overweight and obese children and adolescents. J Pediat Endocrinol Metab 2012; 25: 51-56.

28 Wang X, Liang L, Junfen FU, Lizhong DU. Metabolic syndrome in obese children born large for gestational age. Indian J Pediatr 2007; 74: 561-565.

29 Guerrero-Romero F, Aradillas-Garcia C, Simental-Mendia LE, Monreal-Escalante E, de $\mathrm{CM}$, Rodriguez-Moran M. Birth weight, family history of diabetes, and metabolic syndrome in children and adolescents. J Pediatr 2010; 156: 719-1.

30 Wei JN, Li HY, Sung FC, Lin CC, Chiang CC, Li CY, Chuang LM. Birth weight correlates differently with cardiovascular risk factors in youth. Obesity (Silver Spring) 2007; 15: 1609-6.

31 Seidman DS, Laor A, Gale R, Stevenson DK, Mashiach S, Danon YL. Birth weight, current body weight, and blood pressure in late adolescence. BMJ British Med J 1991; 302: 1235-1237.

32 Renom Espineira A, Fernandes-Rosa FL, Bueno AC, De Souza RM, Moreira AC, De Castro M, Barbieri MA, Bettiol H, Antonini SR. Postnatal growth and cardiometabolic profile in young adults born large for gestational age. Clin Endocrinol 2011; 75 335-341.

33 Euser AM, Dekker FW, Hallan SI. Intrauterine growth restriction: no unifying risk factor for the metabolic syndrome in young adults. Eur J Cardiovasc Prev Rehabil 2010; 17: 314-320.

34 Järvelin M-R, Sovio U, King V, Lauren L, Xu B, McCarthy MI, Hartikainen AL, Laitinen J, Zitting P, Rantakallio P, Elliott P. Early life factors and blood pressure at age 31 years in the 1966 northern Finland birth cohort. Hypertension 2004; 44: 838-846.

35 Fagerudd J, Forsblom C, Pettersson-Fernholm K, Saraheimo M, Waden J, Ronnback M, Rosengård-Bärlund M, Björkesten CG, Thorn L, Wessman M, Groop PH. Low birth weight does not increase the risk of nephropathy in Finnish type 1 diabetic patients. Nephrol Dial Transplant 2006; 21: 2159-5.

36 Hardy R, Kuh D, Langenberg C, Wadsworth ME. Birthweight, childhood social class, and change in adult blood pressure in the 1946 British birth cohort. Lancet 2003; 362: 1178-3.

37 Liew G, Wang JJ, Klein R, Duncan BB, Brancati F, Yeh H-C, Wong TY. The relationship between birthweight and early age-related maculopathy: the atherosclerosis risk in communities study. Ophthalmic epidemiology. Ophthalmic Epidemiol 2008; 15 56-61.

38 Curhan GC, Willett WC, Rimm EB, Spiegelman D, Ascherio AL, Stampfer MJ. Birth weight and adult hypertension, diabetes mellitus, and obesity in US men. Circulation 1996; 94: 3246-3250.

39 Curhan GC, Chertow GM, Willett WC, Spiegelman D, Colditz GA, Manson JE, Speizer FE, Stampfer MJ. Birth weight and adult hypertension and obesity in women. Circulation 1996; 94: 1310-1315.
40 Eriksson J, Forsén T, Tuomilehto J, Osmond C, Barker D. Fetal and childhood growth and hypertension in adult life. Hypertension 2000; 36: 790-794.

41 Eriksson M, Wallander MA, Krakau I, Wedel H, Svardsudd K. Birth weight and cardiovascular risk factors in a cohort followed until 80 years of age: the study of men born in 1913. J Intern Med 2004; 255: 236-236.

42 Rich-Edwards JW, Stampfer MJ, Manson JE, Rosner B, Hankinson SE, Colditz GA Willett WC, Hennekens $\mathrm{CH}$. Birth weight and risk of cardiovascular disease in a cohort of women followed up since 1976. BMJ 1997; 315: 396-400.

43 Innes KE, Byers TE, Marshall JA, Baron A, Orleans M, Hamman RF. Association of a woman's own birth weight with her subsequent risk for pregnancy-induced hypertension. Am J Epidemiol 2003; 158: 861-870.

44 Li C, Huang T-K, Cruz ML, Goran MI. Birth weight, puberty, and systolic blood pressure in children and adolescents: a longitudinal analysis. J Human Hypertension 2006; 20: 444-450.

45 Leon DA, Johansson M, Rasmussen F. Gestational age and growth rate of fetal mass are inversely associated with systolic blood pressure in young adults: an epidemiologic study of 165136 Swedish men aged 18 years. Am J Epidemiol 2000; 152: 597-604.

46 Clausen JO, Borch-Johnsen K, Pedersen O. Relation between Birth Weight and the Insulin Sensitivity Index in a Population Sample of 331 Young, Healthy Caucasians. Am J Epidemiol 1997; 146: 23-31.

47 Leon DA, Koupilova I, Lithell HO, Berglund L, Mohsen R, Vagero D, Lithell UB, McKeigue PM. Failure to realise growth potential in utero and adult obesity in relation to blood pressure in 50 year old Swedish men. BMJ 1996; 312: 401-406.

48 Fall CH, Osmond C, Barker DJ, Clark PM, Hales CN, Stirling Y, Meade TW. Fetal and infant growth and cardiovascular risk factors in women. BMJ 1995; 310: 428-432.

49 Ylihärsilä H, Eriksson JG, Forsén T, Kajantie E, Osmond C, Barker DJP. Selfperpetuating effects of birth size on blood pressure levels in elderly people. Hypertension 2003; 41: 446-450.

50 Bowers K, Liu G, Wang P, Ye T, Tian Z, Liu E, Hu G, Zhang C. Birth weight, postnatal weight change, and risk for high blood pressure among chinese children. Pediatrics 2011; 127: e1272-e1279.

51 Koupilová I, Leon DA, Lithell HO, Berglund L. Size at birth and hypertension in longitudinally followed 50-70-year-old men. Blood Pressure 1997; 6: 223-228.

52 Sørensen HT, Thulstrup AM, Nørgdård B, Engberg M, Madsen KM, Johnsen SP, Olsen $\mathrm{J}$, Lauritzen T. Fetal growth and blood pressure in a Danish population aged 31-51 years. Scandinavian Cardiovascular J 2000; 34: 390-395.

53 Gurven M, Blackwell AD, Rodríguez DE, Stieglitz J, Kaplan H. Does blood pressure inevitably rise with age?: longitudinal evidence among forager-horticulturalists. Hypertension 2012; 60: 25-33.

54 Xiong X, Wightkin J, Magnus JH, Pridjian G, Acuna JM, Buekens P. Birth weight and infant growth: optimal infant weight gain versus optimal infant weight. Maternal Child Health J 2007; 11: 57-63.

55 Ong KK, Ahmed ML, Emmett PM, Preece MA, Dunger DB. Association between postnatal catch-up growth and obesity in childhood: prospective cohort study. BMJ 2000; 320: 967-971.

56 Cnattingius S, Villamor E, Lagerros YT, Wikström A-K, Granath F. High birth weight and obesity-a vicious circle across generations. Int J Obes 2011; 36: 1320-1324.

57 Bouhours-Nouet N, Dufresne S, de Casson FB, Mathieu E, Douay O, Gatelais F, Rouleau S, Coutant R. High birth weight and early postnatal weight gain protect obese children and adolescents from truncal adiposity and insulin resistance: metabolically healthy but obese subjects? Diab Care 2008; 31: 1031-1036. 